\title{
Species Identification of Gram Wilt Complex through ITS Region by PCR-RFLP Analysis
}

\section{Muhammad Jawad ${ }^{1 *}$, Shahid Riaz Malik², Rana Muhammad Atif ${ }^{2}$, Haris Ahmed ${ }^{2}$ and Muhammad Shahzad Afzal ${ }^{3}$}

${ }^{1}$ Crop Science Institute, Pakistan; ${ }^{2}$ University of Agriculture, Faisalabad, Pakistan; ${ }^{3}$ Sugarcane Research Institute, AARI, Faisalabad, Pakistan.

Abstract | Chickpea is the most important pulse legume that serve as dietary protein source for poor farmers
in the developing countries. Yield and production severely challenged by biotic stresses. Wilt complex is the
major biotic factor that contribute significantly in yield loss. Wilt complex is caused by various pathogens,
including diverse type of Fusarium species. Molecular approach is a useful technique for the identification
of wilt complex pathogens. The study conducted to identify the polygenetic association of the pathogens of
chickpea wilt complex. Universal Rice Primers based diversity analysis indicates high polymorphism within
the collected wilt isolates. Primers ITS 1 and ITS 4 generated internal transcribed spacer fragments that
were restricted four restriction enzymes (HhaeI, MboI, BsuRI, HinfI). PCR ITS-RFLP banding pattern
identified two Fusarium species i.e. Fusarium oxysporum and Fusarium solani. In conclusion, PCR-ITS-RFLP
proved to be an efficient and easy technique for the identification of wilt complex pathogens.
Received | June 02, 2020; Accepted | September 18, 2020; Published | October 08, 2020
"Correspondence | Muhammad Jawad, Crop Science Institute, Pakistan; Email: jawwad.parc@gmail.com
Citation | Jawad, M., S.R. Malik, R.M. Atif, H. Ahmed and M.S. Afzal. 2020. Species identification of gram wilt complex through ITS region
by PCR-RFLP analysis. Pakistan Journal of Agricultural Research, 33(4): 770-777.
DOI | http://dx.doi.org/10.17582/journal.pjar/2020/33.4.770.777
Keywords | URP, ITS region, RFLP, Fusarium, Hinfl

\section{Introduction}

$\mathrm{C}$ hickpea or gram is the most important cool season pulse legume of the semi-arid tropics. Its yield and ultimately production is severely challenged by various biotic and abiotic factors. Among biotic factors, gram wilt or chickpea wilt is the most demolishing facultative group of parasites that can cause damage to whole crop under favorable weather conditions (Sharma and Muehlbauer, 2007). Different strains of pathogenic Fusarium species take part in this complex and later cause the root rot and wilting of the host plants. Pathogens of wilt complex are divided into more than 100 forms which are not possible to identify morphologically (Baayen et al., 2000), (Di Pietro et al., 2003), (Lievens et al., 2008). Chickpea wilt is caused by the combination of different pathogens. The most common pathogen of wilt complex is F. oxysporum f. sp. ciceris. Other pathogens includes $F$. solani, Rhizoctonia bataticola, Botrytis cinerea, etc. (Nene et al., 1996). Pathogens attack the plant at two different stages i.e. first at seedling stage (20 -25 days after sowing in the autumn season (Sept-Oct) and second at reproductive stage in the spring season (Feb-Mar). Dry and warm climate is suitable for the spreading of wilt (Pande et al., 2005). It damages the roots of plant and penetrate in the vascular tissues, causing disturbance in root-water relation, leading to reduction/stoppage of movement of water to the aerial parts of the plant. As the result of wilt, yellowing of leaves and drooping of petiole, rachis and leaflets are observed in the infected plant as the disease progress, ultimately plant dies after showing these symptoms. 
In Pakistan, chickpea crop is severely threatened by wilt disease due to the presence of drought conditions in the recent years. It remains a continuous problem due to its saprophytic ability and can remain alive for a very long period of time which can help the pathogen to develop many new physiological races of high resistivity (Bendre and Barhate, 1998).

All the species of Fusarium are both seed and soil born and can survive in the soil for up-to six years without any host (Haware et al., 1996). Due to the survival ability and mode of damage, management of the disease is very difficult by means of fungicides and crop rotation. The cultivation of resistant varieties is the most suitable and efficient way to overcome the losses due to disease (Bakhsh et al., 2007; Nene and Reddy, 1987). However, wilt resistance in chickpea is seriously threatened due to the evolution of new races and species.

Therefore, regular monitoring is needed to identify new isolates from different cultivated geographically regions for efficient resistance breeding program.

There are different approaches to identify the strains of pathogens. However, the most accurate and easiest way to identify and characterize the genetic variation within the pathogens is molecular based approach. These approaches include PCR based ITS-RFLP (internal transcribed spacer -restriction fragment length polymorphism), gene specific amplification, ISSR (inter simple sequence repeat), translation elongation factor 1 alpha (EF-1a) sequencing and AFLP (amplified fragment length polymorphism). Identification of wilt complex strains using ITSRFLP analysis is most precise (Gurjar et al., 2009). The use of universal rice primers (URPs), designed from wild rice genomic sequence has been successfully demonstrated for the dissection of genetic diversity in plants, animals and microbes. Besides, URPs have also proved their worth in characterization of eukaryotic and prokaryotic genomes at specific and intra-specific level (Kang et al., 2001).

Universal Rice Primers (URP) were developed from Korean weedy rice through repetitive sequence of DNA. URP-PCR protocols provides the high reproducibility throughout the thermo-cycling reactions. Under the PCR condition, each single URP primer produced characteristic fingerprints from wide range of genomes containing plants, animals and microbes, indicating its universal applicability.
URP-PCR technology has been applied for accessing genetic diversity of various fungal species.

Restriction Fragment Length Polymorphism (RFLP) detects the polymorphism that results from variation in the DNA sequence recognized by restriction enzymes. Different RFLP reported for detecting the variation in genomic structure for the identification of fungal species.

Genotyping of the isolates using these approaches is not only helpful in identification of microbial species and isolates, but it also generates information that is useful for the disease-resistance breeding program. In this context, the present study was conducted to assess the genetic variability in the pathogens of wilt complex that were collected from chickpea growing areas of Punjab, Pakistan.

\section{Materials and Methods}

\section{Collection, isolation, and DNA extraction of wilted samples}

A total of twenty-three wilted samples were collected from main chickpea growing districts (Bhakkar, Khushab, Jhung and Mianwali). The samples were collected after 25 days of germination. Out of these twenty three disease samples eight were collected from Athara Hazari (Isolate 1, Isolate 2, Isolate 3, Isolate 4, Isolate 5, Isolate 6, Isolate 7 and Isolate 8) and one from Garh More (Isolate 19) Jhung district, four from Bhakar district (Isolate 9, Isolate 10, Isolate 11 and Isolate 12), four from Piplan (Isolate 13, Isolate 14, Isolate 15 and Isolate 16) and two from Harnauli (Isolate 17 and Isolate 18) Mianwali district, and four samples were collected from Adhikot (Isolate 20, Isolate 21, Isolate 22 and Isolate 23) Khushab district. The infected roots of these samples were cut into small pieces of 4 to $5 \mathrm{~cm}$ at collar region and below, and surface sterilized with $2 \%$ sodium hypochlorite solution and in $70 \%$ ethanol solution for 30 seconds respectively. After sterilization samples were dried on sterilized filter paper for 10-20 seconds and placed on petri dishes containing water agar media. After that media containing wilted samples incubated at $25^{\circ} \mathrm{C}$ $\pm 2^{\circ} \mathrm{C}$ for 7-10 days for the preliminary isolation of fungus. The initial fungal growth was further purified on Chickpea Seed Meal Agar (CSMA) medium. For the extraction of DNA, fungal isolates were grow on potato dextrose medium (PDB) to get mycelium (Farooq et al., 2005). 
DNA extraction from fungal cultures

Mycelium was used to extract fungal DNA using CTAB method (Khan et al., 2004). Five to six (5-6) gram of fungal mycelium mass was centrifuged in the tissue lyser (Biospec Product Mini Beadbeater) by adding $1000 \mu \mathrm{l}$ of CTAB in each centrifuge tube for 2 minutes. After grinding, samples were placed at $65^{\circ} \mathrm{C}$ for 45 minutes in water bath. Then $440 \mu \mathrm{l}$ solution of chloroform and isoamyl alcohol (24:1) was added in each centrifuge tube containing fungal DNA and shaken manually for 10 minutes followed by centrifugation at $24000 \mathrm{rpm}$ for 20 minutes. The supernatant from each centrifuge tube was collected in a separate Eppendorf tube. After that $400 \mu \mathrm{l}$ of isopropanol was added in each sample. Eppendorf tubes were shaken manually for 2-3 times and placed at room temperature for 30 minutes. The samples were again centrifuged at $24,000 \mathrm{rpm}$ for 10 minutes and DNA pellet was collected. Then 500 $\mu 1$ of $70 \%$ ethanol was added in each tube having DNA pellet and kept at room temperature for 5 minutes and then centrifuged at 24,000 rpm. After 5 minutes of centrifugation DNA was collected and dried in vacuum dryer for 10 minutes. At the end dried DNA pallets were re-suspended in $100 \mu \mathrm{l}$ of TE buffer.

\section{Universal rice primers-based genetic diversity analysis}

Ten Universal Rice Primers URPs were used to find out the genetic diversity of the collected isolates (Table 1). Each URP reaction contained $100 \mathrm{ng}$ of DNA, $0.4 \mu \mathrm{M}$ primer, $0.2 \mathrm{mM}$ of dNTPs, $1 \mathrm{U}$ Taq DNA polymerase, $50 \mathrm{mM} \mathrm{KCl,} 2.5 \mathrm{mM} \mathrm{MgCl2}$, $10 \mathrm{mM}$ Tris- $\mathrm{HCl} \mathrm{pH} 8.8$ and PCR grade water up to final volume of $25 \mu$. The amplification reactions were conducted in thermal cycler (MyGene MG 96 $\mathrm{G})$. The thermal cycler was programed at $94^{\circ} \mathrm{C}$ for 3 minutes for initial denaturation $55^{\circ} \mathrm{C}$ for 1 minute for annealing followed by 40 PCR cycles. Primer extension temperature was $72^{\circ} \mathrm{C}$ for 2 minutes, denaturation temperature was $94^{\circ} \mathrm{C}$ for 1 minute, extension temperature was $72{ }^{\circ} \mathrm{C}$ for 2 minutes and final extension temperature were $72^{\circ} \mathrm{C}$ for 10 minutes. PCR products were visualized under UV light on $1.5 \%$ agarose. $1 \mathrm{~kb}+$ DNA ladder (Enzynomics: Cat \# DM003) was used to differentiate PCR product and estimate the size of the bands. On the basis of banding patterns of URPs, dendrogram of unweighted pair group method of arithmetic mean (UPGMA) using SPSS 16.0 was constructed (Singh et al., 2016).
Amplification of ITS region and its restriction digestionbased species identification

ITS region from the genomes of the collected isolates were amplified using ITS- 1 and ITS-4 primers (Table 1) (Datta and Lal, 2012). The PCR was initiated with initial denaturation temperature at $95{ }^{\circ} \mathrm{C}$ for $3 \mathrm{~min}$ followed by 30 cycles with primer annealing for 40 secs at $58^{\circ} \mathrm{C}$, extension for 40 secs at $72^{\circ} \mathrm{C}$, denaturation for $40 \mathrm{sec}$ at $94^{\circ} \mathrm{C}$ and final extension for 5 minutes at $72{ }^{\circ} \mathrm{C}$. The amplified fragments restricted using restriction fragment length polymorphic primers (MboI, BsuRI, HhaI and HinfI) (Chehri et al., 2011). For the restriction of fragments, 2-3 $\mu \mathrm{l}$ of restriction enzymes were separately applied in the microfuge tube containing $10 \mu \mathrm{l}$ of ITS PCR product along with $18 \mu \mathrm{l}$ of nuclease free water and $2 \mu \mathrm{l}$ of $10 \mathrm{x}$ buffer and incubated at $37^{\circ} \mathrm{C}$ for 16 hours. The restricted fragments were visualized using 1.4\% agarose gel under UV light and the molecular weight of each band were calculated using UVI BandMap 1.1 software.

\section{Table 1: List of Primers along with sequence.}

$\begin{array}{lll}\text { Sr.\# } & \text { Primer } & \text { Sequence } \\ 1 & \text { URP-21 } & \text { ATCCAAGGTCCGAGACAACC } \\ 2 & \text { URP-22 } & \text { GTGTGCGATCAGTTGCTGGG } \\ 3 & \text { URP-23 } & \text { CCCAGCAACTGATCGCACAC } \\ 4 & \text { URP-24 } & \text { AGGACTCGATAACAGGCTCC } \\ 5 & \text { URP-25 } & \text { GGCAAGCTGGTGGGAGGTAC } \\ 6 & \text { URP-26 } & \text { ATGTGTGCGATCAGTTGCTG } \\ 7 & \text { URP-27 } & \text { TACATCGCAAGTGACACAGG } \\ 8 & \text { URP-28 } & \text { AATGTGGGCAAGCTGGTGGT } \\ 9 & \text { URP-29 } & \text { GATGTGTTCTTGGAGCCTGT } \\ 10 & \text { URP-30 } & \text { GGACAAGAAGAGGATGTGGA } \\ 11 & \text { ITS-1 } & \text { TCCGTAGGTGAACCTTGCGG } \\ 12 & \text { ITS-4 } & \text { TCCTCCGCTTATTGATATGC }\end{array}$

\section{Results and Discussion}

\section{URP analysis}

A comprehensive survey of the major chickpea growing area in Pakistan (Thal region) was carried out to identify the chickpea fields affected by wilt. The genetic diversity of collected isolates were determined using a total of 10 different URPs. A dendrogram was developed from URPs data that indicates maximum polymorphism present among the isolates (Figure 1). Dendrogram grouped the isolates into ten clusters. Isolate 14, 17 and 18 shared same group showing monomorphism. Other isolates were mostly polymorphic and isolate 1 and 11 showed maximum polymorphism with other isolates. 


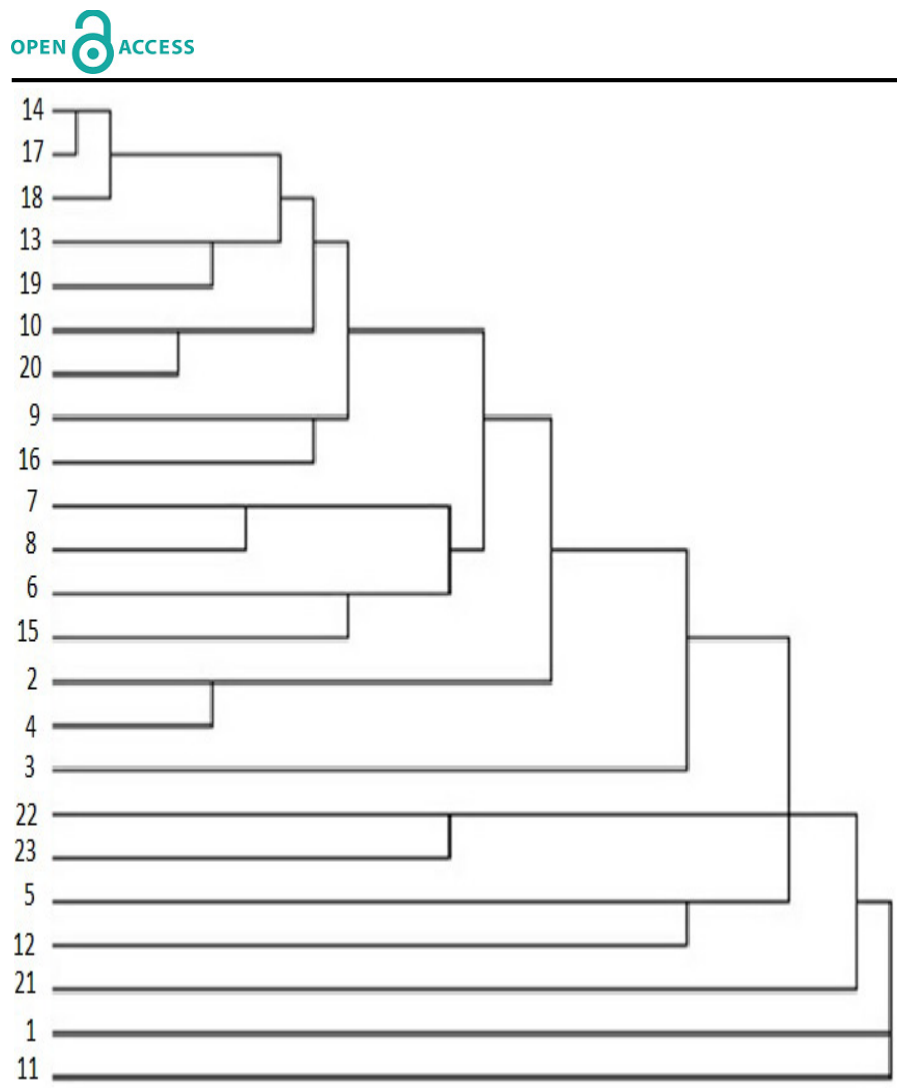

Figure 1: UPGMA dendrogram of collected isolates based on Universal Rice Primers.

\section{Species identification}

The Fusarium species were identified based on band size produced with the amplification of ITS primers (Table 1).ITS primers gave the amplification product to all the isolates. Isolate $1,3,5$ and 12 produce the band size near 650 base pairs. Isolate $2,6,7,8,16$, 19, 22 and 23 showed the band size near 600 base pairs. Isolate 11 and 21 produced the band size near 790 base pairs and isolate 20 gave the amplification product of almost 400 base pairs (Figure 2A). These PCR-ITS amplicons were restricted with four restriction enzymes and different sizes of bands were produced. With HhaeI restriction enzyme, isolate 1 , 3,5 and 11 produces two bands with a size of nearly 430 base pairs and 160 base pairs. Isolates 2, 6, 7, 8, $16,19,20,22$ and 23 also produce two restriction fragments, one with a band size of almost 395 base pairs and second with a band size of 190 base 2 pairs. Two bands of 465 and 155 base pairs were produced by isolate 11 . Isolate 21 produces three restriction fragments with this restriction enzyme with a band size of 335 base pairs, 150 base pairs and 139 base pairs (Figure 2B). When these isolates restricted with BsuRI restriction enzyme, isolate 1,3 , $6,7,8,16,19,22$ and 23 produced single band with a size of nearly 480 base pairs. Isolate 5 produced two bands, one with a size of almost 360 base pairs and other with a size of almost 289 base pairs.

A

B

20000
15000
10004
8500
65004
5000
4000
2000
1004
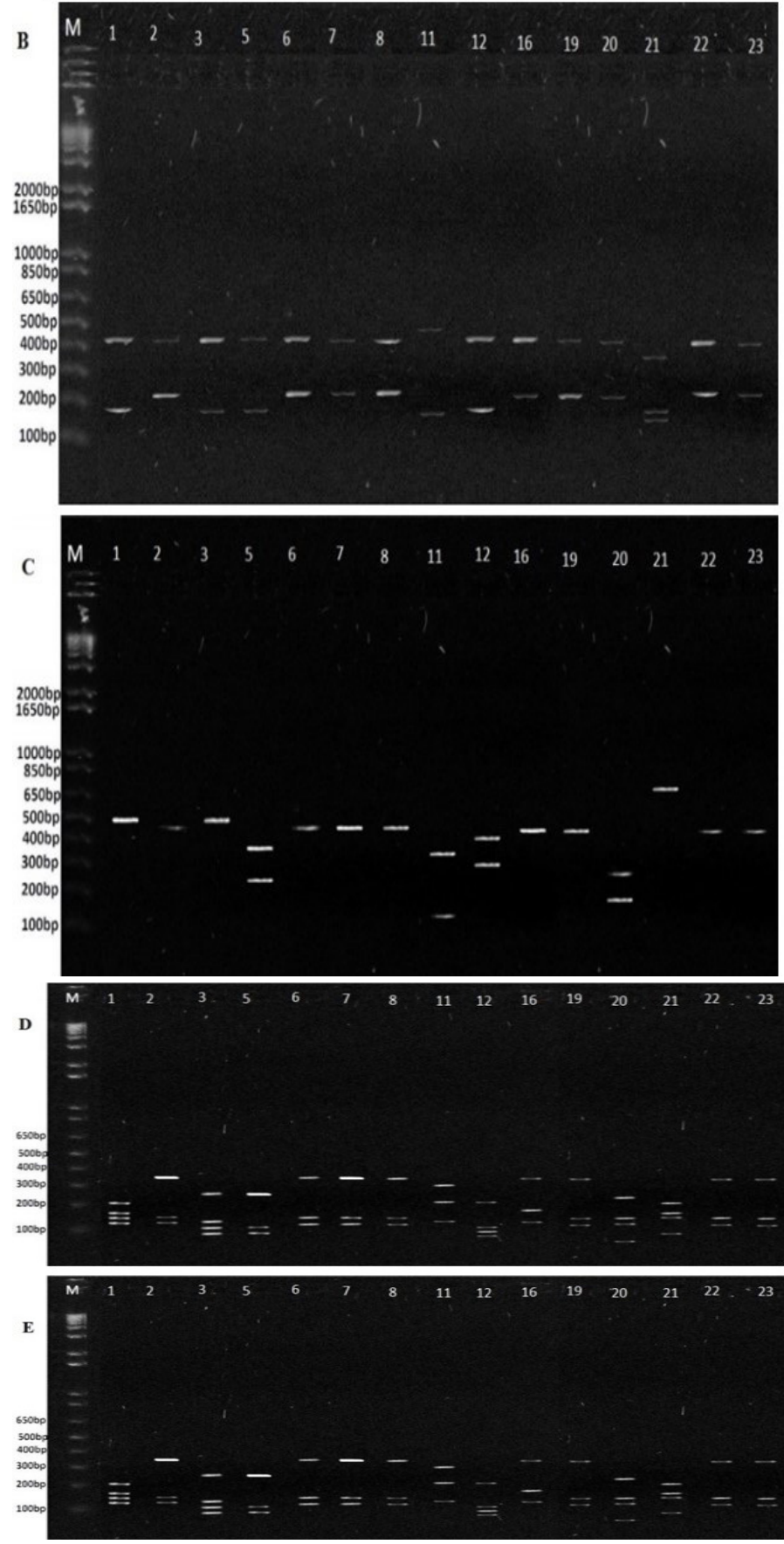

Figure 2: Agarose gel showing (A) amplification of ITS regions (ITS1 and ITS-4) and restriction pattern of PCR-amplification product digested with HhaeI (B); BsuRI (C); HinfI (D) and MboI (E). 
Isolate 11 also produced two fragments with a size of 344 base pairs and 125 base pairs. Two bands of 380 base pairs and 290 base pairs were produced in isolate 12 while two fragments of 269 and 168 base pairs were produced in isolate 20. Isolate 21 produces a single band with a size of almost 720 base pairs (Figure 2C). More than two bands were produced in each isolate when treated with restriction enzyme HinfI. Isolate 1 produced four fragments with a size of 221 base pairs, 168 base pairs, 125 base pairs and 115 base pairs. Isolate 2, 6, 7, 8, 19, 22 and 23 produced three bands of almost 350 base pairs, 130 base pairs and 119 base pairs. Isolate 3 produced four bands of 210 base pairs, 119 base pairs, 105 base pairs and 91 base pairs. Isolate 5 produced three bands of 276 base pairs, 109 base pairs and 94 base pairs. Three bands of 321 base pairs, 228 base pairs and 119 base pairs were produced in isolate 11 . Isolate 12 produced four bands of 221 base pairs, 108 base pairs, 88 base pairs and 71 base pairs. Isolate 20 and 21 also produced four fragments each with a band size of 250 base pairs, 113 base pairs, 107 base pairs, 72 base pairs and 225 base pairs, 156 base pairs, 148 base pairs and 89 base pairs, respectively. (Figure 2D). With MboI restriction enzyme, the ITS-PCR fragment of isolate 1 cut into two fragments of 344 base pairs and 216 base pairs. Isolate 2 restricted into two bands of 416 base pairs and 216 base pairs. Isolate 3, 5 and 12 produced two bands of 390 base pairs and 255 base pairs. Isolate $6,7,8,16,19,22$ and 23 splits into two fragments having 450 and 225 base pairs size. MboI cuts ITS-PCR fragment of Isolate 2 and 7 into three bands of 459 base pairs, 192 base pairs and 152 base pairs. Isolate 21 splits into two segments of 365 and 284 base pairs (Figure 2E). Similar studies were conducted by (Chehri et al., 2011) and (Abd-Elsalam et al., 2003) and reported the band size of different Fusarium species. If we correlate our study with them, we can conclude that isolate $2,6,7,8,16,19,22$ and 23 may be belongs to $F$. oxysporum on the basis of ITS-PCR amplification product and fragments produced by restriction enzymes (Table 2). Isolate 2 does not behave like F. oxysporum when treated with HinfI restriction enzyme (Table 2). In the contrary to this, isolate 20 shows similar banding pattern like F. oxysporum only when treated with HhaeI restriction enzyme. ITS-RFLP PCR produced similar banding pattern like F. solani in isolate 1, 3, 5 and 12. Isolate 1 and 3 produced F. solani like banding pattern when fragments 1 were restricted with BsuRI restriction enzyme and isolate 3 produced similar banding pattern to $F$. solani when restricted with HinfI restriction enzyme (Table 2). But overall, we can conclude that isolate $1,3,5$ and 12 might be belongs to F. solani (Table 2). The ITS-RFLP PCR of other isolates does not show any similarity to the banding pattern of ITS -RFLP of any reported Fusarium species. Two restriction enzymes EcoRI and HhaeIII and amplified ITS regions were used to study the genetic diversity of F. solani (Brasileiro et al., 2004). (Zarrin et al., 2016) identified five Fusarium species using ITS1 and ITS4 primers and two restriction enzymes HhaeIII and SmaI.

Seventy isolates of Fussarium oxysporium f.sp. ciceris (Foc) were characterized using universal rice primers (URPs), random amplified polymorphic DNA, simple sequence repeat and inter simple sequence repeat (Dubey et al., 2012). The UPRs gave 100\% polymorphism in all the isolates in accordance with other molecular markers used. These results show similarity with our findings as URPs are useful molecular markers for characterization.

(Baite et al., 2017) analyze the genetic diversity of 25 Ascochyta rabei isolates with universal rice primers and simple sequence repeats. Both the molecular markers showed high similarity among these isolates. Their results are opposite to our findings regarding diversity but showing the reliability of UR Primers for the diversity analysis.

Table 2: Identified isolates with ITS regions and restricted fragments.

$\begin{array}{llllll}\text { Isolates } & \text { ITS Primer } & \text { BsuRI } & \text { HhaeI } & \text { MboI } & \text { HinfI } \\ 1 & \text { F.S } & \text { F.S } & \text { F.S } & \text { U.I } & \text { U.I } \\ 2 & \text { F.O } & \text { F.O } & \text { F.O } & \text { F.O } & \text { U.I } \\ 3 & \text { F.S } & \text { F.S } & \text { F.S } & \text { F.S } & \text { F.S } \\ 5 & \text { F.S } & \text { U.I } & \text { F.S } & \text { F.S } & \text { U.I } \\ 6 & \text { F.O } & \text { F.O } & \text { F.O } & \text { F.O } & \text { F.O } \\ 7 & \text { F.O } & \text { F.O } & \text { F.O } & \text { F.O } & \text { F.O } \\ 8 & \text { F.O } & \text { F.O } & \text { F.O } & \text { F.O } & \text { F.O } \\ 11 & \text { U.I } & \text { U.I } & \text { U.I } & \text { U.I } & \text { U.I } \\ 12 & \text { F.S } & \text { U.I } & \text { F.S } & \text { F.S } & \text { U.I } \\ 16 & \text { F.O } & \text { F.O } & \text { F.O } & \text { F.O } & \text { U.I } \\ 19 & \text { F.O } & \text { F.O } & \text { F.O } & \text { F.O } & \text { F.O } \\ 20 & \text { U.I } & \text { U.I } & \text { F.O } & \text { U.I } & \text { U.I } \\ 21 & \text { U.I } & \text { U.I } & \text { U.I } & \text { F.S } & \text { U.I } \\ 22 & \text { F.O } & \text { F.O } & \text { F.O } & \text { F.O } & \text { F.O } \\ 23 & \text { F.O } & \text { F.O } & \text { F.O } & \text { F.O } & \text { F.O }\end{array}$

F.S: Fussarium Solonai; F. O: Fussarium oxysporium; U.I: Un-identified. 
Different URPs were also employed by to evaluate the genetic diversity of Ascochyta rabiei and found high polymorphism among the isolates (Ali et al., 2013). They also proved that the UPRs can successfully be utilized for the diversity analysis. Because of the reliability of URPs, these primers were also used by (Mann et al., 2014) for molecular characterization of B. sorokiniana and found maximum genetic diversity. These different studies show that URPs are efficient molecular approach for the estimation of genetic diversity.

In this study, the variation in the ITS regions and restricted fragments were successfully employed for the recognition of Fusarium species. Previously these approaches were also employed (Chehri et al., 2011). They identified different species of Fusarium through PCR-ITS-RFLP analysis. Further they conformed identified species through morphological characterization. The identified species were Fusarium oxysporum, Fusarium proliferatum, Fusarium equiseti, Fusarium semitectum and Fusarium solani. Banding pattern of F. oxysporum and F. solnai species developed through PCR-ITS-RFLP method were exactly in accordance to our study. But we did not get similar banding pattern to other identified species.

\section{(Dubey et al., 2014) identified Fussarium oxysporum} races through PCR-ITS-RFLP analysis. Most of the isolates in their study were belongs to race 1. If we corelate their findings with our study, we can say that ITS region and restricted fragments can successfully be employed for species and race identification of Fussarium species. Fusarium species were also identified in tomato through PCR-ITSRFLP method and random amplified polymorphic DNA analysis (Singhaa et al., 2016). They identified F. oxysporum, $F$. equiseti and $F$. proliferatum. The PCR-ITS-RFLP pattern of $F$. oxysporum is like our identified F. oxysporum specie.

ITS regions are good target for the identification of fungi. These regions are mostly conserved within different species of fungus. There are multiple copies of these regions are present in most of the fungal genome which is very useful for the taxonomic classification for the majority of fungi (Balajee et al., 2009).

\section{Conclusions and Recommendations}

The ITS region and restricted fragments with four restriction enzymes conformed in this study to be a suitable molecular tool for the identification of Fusarium species. Additionally, there are many sequences available for this locus in Genbank, which can be used for the comparison of results. In the present study some isolates are not identified that can be identified by sequencing of ITS fragments and blasting of these sequences to sequence alignment tool (BLAST NCBI). The identified isolates can be rechecked using other species identification techniques (Serial analysis of gene expression, DNA barcoding). The present study also indicates that there is a mixed population of Fusarium species in different chickpea growing areas of Punjab, Pakistan. Thus, we can conclude that the wilt in chickpea is caused by the complex of different Fusarium species.

\section{Novelty Statement}

Wilt complex is major biotic factor that contributes to yield loss. For chickpea resistant breeding program, identification of species in wilt complex is very much important. The PCR RFLP analysis is advanced molecular approach to identify the fusarium races.

\section{Author's Contribution}

Muhammad Jawad data recording and wrote the article. Shahid Riaz Malik reviewed the article. Muhammad Atif technical guidance. Haris Ahmed statistical analysis and data recording. Shahzad Afzal proof reading.

\section{Conflict of interest}

The authors have declared no conflict of interest.

\section{References}

Abd-Elsalam, K.A., N.A. Ibrahim, M.A. AbdelSatar, M.S. Khalil and J.A. Verreet. 2003. PCR identification of Fusarium genus based on nuclear ribosomal-DNA sequence data. Afr. J. Biotechnol., 2: 82-85. https://doi.org/10.5897/ AJB2003.000-1016

Ali, H., S.S. Alam and N. Iqbal. 2013. Genetic and pathogenic variability of ascochyta rabiei isolates from Pakistan and Syria as detected by universal rice primers. J. Plant Pathol. Microb., 4: 1-3.

Baayen, R.P., K. O’Donnell, P.J.M. Bonants, E. 
Cigelnik, L.P.N.M. Kroon, J.A. Roebroeck and C. Waalwijk. 2000. Gene genealogies and AFLP analyses in the Fusarium oxysporum complex identify monophyletic and nonmonophyletic formae speciales causing wilt and rot disease. Phytopathology, 90: 891-900. https://doi. org/10.1094/PHYTO.2000.90.8.891

Baite, M.S., S.C. Dubey and B.K. Upadhyay. 2017. Genetic diversity of Ascochyta rabiei causing blight of chickpea in India. Res. J. Biotech., 12: 29-37.

Bakhsh, A., S.M. Iqbal and I.K. Haq. 2007. Evaluation of chickpea germplasm for wilt resistance. Pak. J. Bot. 39: 583-593.

Balajee, S.A., A.M. Borman, M.E. Brandt, J. Cano, M. Cuenca-Estrella, E. Dannaoui, J. Guarro, G. Haase, C.C. Kibbler and W. Meyer. 2009. Sequence-based identification of aspergillus, fusarium, and mucorales species in the clinical mycology laboratory: Where are we and where should we go from here? J. Clin. Microbiol., 47: 877-884. https://doi.org/10.1128/JCM.0168508

Bendre, N.J. and B.G. Barhate. 1998. A souvenir on Disease Management in chickpea. M.P.K.V., Rahuri during 10 ${ }^{\text {th }}$ Dec. 1998.

Brasileiro, T.R.V.B., M.R.M. Coimbra, D.M.J.M. Antonio and D.O.N. Tinti. 2004. Genetic variability within Fusarium solani species as revealed by PCR-fingerprinting based on PCR markers. Braz. J. Microbiol., 35: 205-210. https://doi.org/10.1590/S151783822004000200006

Chehri, K., B. Salleh, T. Yli-Mattila, K.R.N. Reddy and S. Abbasi. 2011. Molecular characterization of pathogenic Fusarium species in cucurbit plants from Kermanshah province, Iran. Saudi J. Biol. Sci., 18: 341-351. https://doi. org/10.1016/j.sjbs.2011.01.007

Datta,J. and N. Lal. 2012. Application of molecular markers for genetic discriminationi of fusarium wilt pathogen races affecting chickpea and pigeonpea in major regions of India. Cell. Mol. Biol., 58: 55-65.

Di Pietro,A., M.P.Madrid,Z.Caracuel,J.DelgadoJarana and M.I.J. Roncero. 2003. Fusarium oxysporum: Exploring the molecular arsenal of a vascular wilt fungus. Mol. Plant Pathol., pp. 315-325. https://doi.org/10.1046/j.1364- 3703.2003.00180.x

Dubey, S.C., K. Priyanka and V. Singh. 2014. Phylogenetic relationship between different race representative populations of Fusarium oxysporum f. sp. ciceris in respect of translation elongation factor- $1 \alpha, \beta$-tubulin, and internal transcribed spacer region genes. Arch. Microbiol., pp. 196. https://doi.org/10.1007/ s00203-014-0976-0

Dubey, S., P. Kumari, S. Vivek and S. Birendra. 2012. Race profiling and molecular diversity analysis of fusarium oxysporum f.sp. ciceris Causing Wilt in Chickpea. J. Phytopathol., pp. 160. https://doi.org/10.1111/j.14390434.2012.01954.x

Farooq, S., M.S. Iqbal and A.C. Rauf. 2005. Physiological studies of Fusarium oxysporum F. sp. Ciceri. Int. J. Agric. Biol., 7: 275-277.

Gurjar, G., M. Barve, A. Giri and V. Gupta. 2009. Identification of Indian pathogenic races of Fusarium oxysporum f. sp. ciceris with gene specific, ITS and random markers. Mycologia, 101: 484-495. https://doi.org/10.3852/08-085

Haware, M.P., Y.L. Nene and M. Natarajan. 1996. The survival of Fusarium oxysporum f. sp. ciceri in the soil in the absence of chickpea. Phytopathol. Mediterr., 35(1): 9-12.

Kang, H.W., D.S. Park, Y.J. Park, C.H. You, B.M. Lee, M.Y. Eun and S.J. Go. 2001. Genomic differentiation among oyster mushroom (Pleurotus spp.) cultivars released in Korea by URP-PCR fingerprinting. Mycobiology, 25: 85-89. https://doi.org/10.1080/12298093.200 1.12015766

Khan, I.A., F.S. Awan, A. Ahmad and A.A. Khan. 2004. A Modified mini-prep method for economical and rapid extraction of genomic DNA in plants. Plant Mol. Biol., 22: 89a-89e. https://doi.org/10.1007/BF02773355

Lievens, B., M. Rep and B.P.H.J. Thomma. 2008. Recent developments in the molecular discrimination of formae speciales of Fusarium oxysporum. Pest Manage. Sci., 64: 781-788. https://doi.org/10.1002/ps.1564

Mann, B.M., C.C. Spadari, T. Feltrin, A.P.G. Frazzon,J.C. Germani and S.T.V.D. Sand.2014. Genetic variability of Bipolaris sorokiniana isolates using URP-PCR. Trop. Plant Pathol., 39: 163-171. https://doi.org/10.1590/S198256762014000200007 
Nene, Y.L. and M.V. Reddy. 1987. Chickpea diseases and their control. In: The chickpea. M.C. Saxena and K.B. Singh (ed.) CAB Int., Oxon, UK. pp. 233-270.

Nene, Y.L., V.K. Sheila and S.B. Sharma. 1996. A world list of chickpea and pigeon pea pathogens. Int. Crops Res. Inst. Semi-Arid Trop., 5: 27.

Pande, S., K.H.M. Siddique, G.K. Kishore, B. Bayaa, P.M. Gaur, C.L.L. Gowda, T.W. Bretag and J.H. Crouch 2005. Ascochyta blight of chickpea (Cicer arietinum L.): A review of biology, pathogenicity and disease management. Aust. J. Agric. Res., 56: 317-332. https://doi. org/10.1071/AR04143

Sharma, K.D. and F.J. Muehlbauer. 2007. Fusarium wilt of chickpea: physiological specialization, genetics of resistance and resistance gene tagging. Euphytica, 157: 1-14. https://doi. org/10.1007/s10681-007-9401-y
Singh, B.P., S. Ratul, Y. Mukesh, S. Rakesh, V.S. Chauhan and K.A. Dilip. 2016. Molecular characterization of Fusarium oxysporum f. sp. ciceri causing wilt of chickpea. Afr. J. Biotechnol., 5: 497-502.

Singhaa, I.M., K. Yelena, G.U. Bala, D. Jayshree and C.K. Mohan. 2016. Identification and characterization of Fusarium sp. using ITS and RAPD causing fusarium wilt of tomato isolated from Assam, North East India. Genet. Eng. Biotechnol. J., 14: 99-105. https://doi. org/10.1016/j.jgeb.2016.07.001

Zarrin, M., G. Farzaneh and F. Sama. 2016. Analysis of the rDNA internal transcribed spacer region of the Fusarium species by polymerase chain reaction-restriction fragment length polymorphism. Biomed. Rep. 4: 471474. https://doi.org/10.3892/br.2016.615 